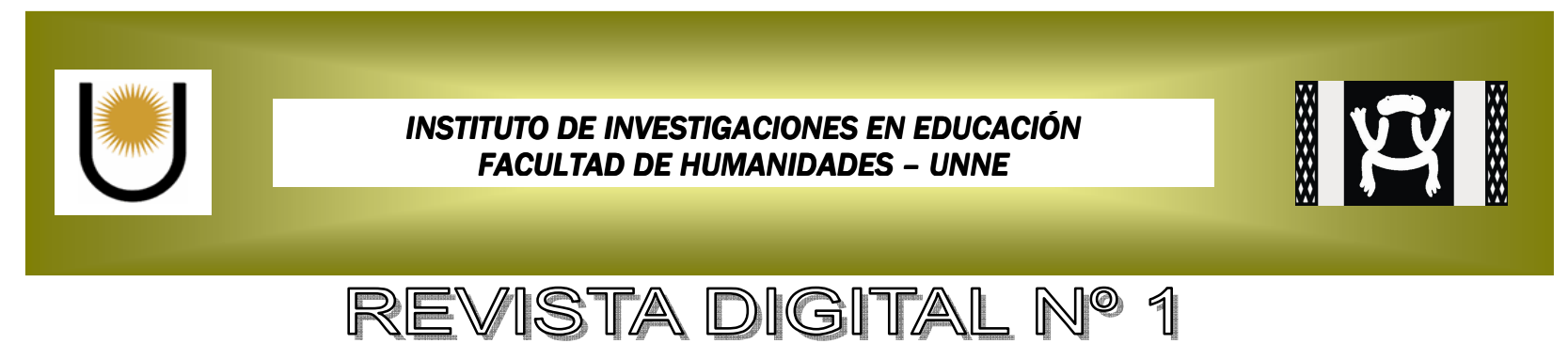

\title{
Título: Las relaciones de poder en la relación pedagógica ${ }^{1}$
}

\author{
Autora: Mónica Beatriz Vargas
}

Este resumen corresponde a la tesis de grado cuyo tema fue Las relaciones de poder en la relación pedagógica. En la misma me planteé como problemática el modo en que las relaciones de poder atraviesan y configuran la relación pedagógica y la esbocé como un camino que me permitiera analizar las relaciones de poder que atraviesan la relación pedagógica en una institución escolar particular, con un grupo clase singular.

Me propuse como objetivos reconocer los modos en que dichas relaciones de poder atraviesan y configuran la relación pedagógica y avanzar en este conocimiento a fin de configurar cierta información que enriquezca el diseño de acciones referidas al campo de la didáctica en la formación docente.

Realicé este trabajo en un $6^{\circ}$ año de EGB 2, con 25 alumnos en el turno tarde. Llevé a cabo observaciones en diferentes espacios institucionales y entrevistas en profundidad a docentes y alumnos del mencionado curso y a los directivos de la escuela.

El enfoque metodológico elegido ha sido esencialmente cualitativo, investigación exploratoria a partir de un caso en profundidad, el que brindó el sustento empírico que permitió la formulación de hipótesis y el descubrimiento de aspectos del problema a investigar. ${ }^{2}$

El proceso de análisis me permitió plantear como conjetura que las pautas que se marcan en la relación pedagógica están atravesadas por ciertos modos en que se manifiestan las relaciones de poder. Estos modos son: violencia física - violencia simbólica y apelación a la culpabilidad.

Estas relaciones reticulares se presentan entre los directivos y los docentes y entre estos y los alumnos, mostrando ciertos caminos que esta relación tiene que seguir. La escala jerárquica emerge como significativa y parece dar lugar a un juego de tensiones al interior de los campos de poder, según la posición que cada uno ocupa en los mismos y en el que cada uno lucha por ascender o conservar su lugar en esta relación de poder. El control está en íntima relación con la posición jerárquica que tienen los actores y con la cuota de poder que tienen al interior de estas relaciones. Tanto los docentes como los alumnos manifiestan que el control que se ejerce sobre estos últimos es explícito y está pautado institucionalmente. Este control no es sólo hacia el alumno. Por parte de los directivos existe asimismo, un control hacia los docentes. Este control tiene que ver en cierto modo con lo que la sociedad solicita a la institución escuela para poder disciplinar al sujeto y que al decir de Foucault, la escuela se convierte en el espacio propicio para tal cometido. Es decir que el control que se ejerce sobre los sujetos organizando

\footnotetext{
${ }^{1}$ Este trabajo fue dirigido por la Especialista María Cristina Alonso. Prof. titular de la cátedra Grupos e Instituciones Educativas y Prof. adjunta de la cátedra Didáctica II, ambas de la carrera Profesorado y Licenciatura en Ciencias de la Educación- Facultad de Humanidades. UNNE

2 "La postura metodológica de esta concepción es la del examen directo del mundo empírico social entendiendo que tal estudio permite al especialista satisfacer todos los requisitos básicos de la ciencia empírica: enfrentarse a un mundo susceptible de observación y análisis, suscitar problemas con respecto al mismo, reunir los datos necesarios a través de un examen detenido y disciplinado, descubrir relaciones entre las respectivas categorías de los datos, formular proposiciones respecto de esas relaciones, incorporarlas a un sistema teórico y verificar problemas, datos, relaciones, proposiciones y teorías por medio de un nuevo examen del mundo empírico." VASILACHIS de Gialdino, I., (1993) Métodos cualitativos I. Los problemas teórico metodológico. Buenos Aires. Centro Editor de América Latina. (pp. 58)
}

facultad de Humanidades - u.N.Ne
Correo electrónico: investigacion_educativa@hum.unne.edu.ar


sus tiempos, espacios y actividades, tiene como finalidad el disciplinamiento y la interiorización de ciertas normas. De algún modo estos mecanismos pautan y regulan las relaciones entre el docente y los alumnos.

Un ejemplo ilustrativo es el caso de una docente que ata (literalmente) a sus alumnos a la silla hasta que la soga queda interiorizada de tal modo que los alumnos piensan que están atados y "la soga la tienen en la cabeza", según sus propias palabras. Este disciplinamiento ejercido por el docente hacia el alumno a través de la violencia física, es el mecanismo utilizado y el que le permite controlar sus movimientos.

Por otra parte si tenemos en cuenta como expresa $\mathrm{Mendel}^{3}$ que la escuela tiene como una de sus funciones más importantes la de socialización del niño y que por lo mismo es una institución estratégica, podemos expresar que el control que se manifiesta en la relación pedagógica que nos ocupa como "caso en estudio" es una apelación a la culpabilidad. Pareciera además reproducir una estructura psicofamiliar en la que cada uno de los integrantes, a partir de ese lugar que ocupa en la "familia", estaría ejerciendo el poder: el directivo hacia los integrantes del par pedagógico, el docente hacia el alumno y hacia el directivo cuando transfieren la resolución de las tareas en ellos y los alumnos en la resistencia que oponen a las normas y al control. Por encima de todo está la figura protectora de los directivos que son los que brindan las soluciones a todas las situaciones obstaculizadoras que se presentan. La cuestión es que ninguno de estos actores parece cuestionarse esta situación planteada.

El centro de este control estaría dado además por una violencia física y simbólica y continuando en la línea de análisis que nos permiten los conceptos mendelianos, no se estaría favoreciendo una socialización no - identificatoria. La socialización identificatoria impide alcanzar la estructuración de un dispositivo que permita la conformación de grupos homogéneos en los que tanto los alumnos como los docentes pudieran comunicarse intra grupo y con los docentes ${ }^{4}$ para ejercer el actopoder. Es decir que cada uno de los integrantes de esta relación pedagógica: el docente en su tarea de enseñante, el alumno en su rol de alumno y los directivos en su rol de conducción, logren tener poder sobre sus actos y propiciar de este modo un personalidad psicosocial en cada uno de ellos. Tendría que ser la escuela la institución estratégica, como expresa Mendel, en donde se logre cumplir no sólo la tarea de instrucción y aprendizaje, sino también que se lleve a cabo la otra función específica: la de socializar pero favoreciendo una socialización que permita el fortalecimiento de una personalidad psicosocial. Esta violencia tanto física como simbólica propicia el fortalecimiento de una personalidad psicofamiliar, en la que las figuras jerárquicas de la sociedad son las representantes de esa Autoridad internalizada, autoridad estructurada durante la primera infancia y conformada a partir de las imagos arcaicas - buenas y malas - maternas y paternas. En este caso estas figuras están siendo representadas por los docentes y directivos. Es decir, no se propicia en el otro la apropiación del acto y de ese modo se fortalece una personalidad infantilizada, que excluye en el otro la responsabilidad y el crecimiento. Para esto se apela a la culpa inconsciente, al temor a la desobediencia de la figura paterna internalizada.

El aporte de este trabajo estaría dado por la posibilidad de ofrecer un análisis acerca de cómo se presentan estas relaciones de poder en la relación pedagógica, las que muchas veces son naturalizadas en un contexto particular en el que el sentido de justicia se estructura a través de la norma, concibiéndola como un mediatizador del poder disciplinar del docente y no como un mediatizador de construcción de personalidad psicosocial.

\footnotetext{
${ }^{3}$ MENDEL, G. ((1996); Sociopsicoanálisis y Educación; Buenos Aires; Ed. Novedades Educativas, p: 11 - 12.
}

${ }^{4}$ Ídem, p. $13-14$ 